\title{
Stathmin overexpression is associated with growth, invasion and metastasis of lung adenocarcinoma
}

\author{
Lin Yurong ${ }^{1}$, Rong Biaoxue ${ }^{1}$, Li Wei ${ }^{1}$, Ming Zongjuan ${ }^{1}$, Shi Hongyang ${ }^{1}$, Fang Ping ${ }^{1}$, \\ Gao Wenlong ${ }^{2}$, Yang Shuanying ${ }^{1}$, Li Zongfang ${ }^{3}$ \\ ${ }^{1}$ Department of Respiratory Medicine, Second Affiliated Hospital, Xi'an Jiaotong University, Xi'an, China \\ ${ }^{2}$ Department of Statistics and Epidemiology, Medical College, Lanzhou University, Lanzhou, China \\ ${ }^{3}$ Department of Elderly Surgery, Second Affiliated Hospital, Xi'an Jiaotong University, Xi'an, China \\ Correspondence to: Yang Shuanying, email: yangshuanying66@126.com, yangshuanying66@163.com \\ Keywords: stathmin, lung adenocarcinoma, shRNA, tumor growth, proliferation
}

Received: February 21, $2016 \quad$ Accepted: July 09, $2016 \quad$ Published: August 02, 2016

Copyright: Yurong et al. This is an open-access article distributed under the terms of the Creative Commons Attribution License (CC-BY), which permits unrestricted use, distribution, and reproduction in any medium, provided the original author and source are credited

\section{ABSTRACT}

Stathmin has been investigated as a tumor biomarker because it appear to be associated with tumorigenesis; however, the effect of stathmin in lung adenocarcinoma (LAC) remains poorly understood. The purpose of this study was to examine the expression of stathmin in lung adenocarcinoma, and to disclose the relationship between them. The expression of stathmin was examined by RTPCR, IHC and Western blot. Furthermore, small interfering RNA (shRNA)-mediated silencing of stathmin was employed in LAC cells to investigate cell proliferation, invasion and apoptosis. In this study, we showed that overexpression of stathmin was significantly associated with poorly differentiated, lymph node metastasis and advance TNM stages of lung adenocarcinoma. And silencing of stathmin expression inhibited the proliferation, migration and invasion of lung adenocarcinoma PC-9 cells, and retarded the growth of PC-9 cells xenografts in nude mice. Additionally, the anticarcinogenic efficacy of stathmin silencing might be involved in P38 and MMP2 signaling pathways. In conclusion, these results showed that stathmin expression was significantly up-regulated in LAC, which may act as a biomarker for LAC. Furthermore, silence of stathmin inhibiting LAC cell growth indicated that stathmin may be a promising molecular target for LAC therapy.

\section{INTRODUCTION}

Lung cancer is a major public health problem in China, which has a high mortality and a high morbidity. It is reported that there will be about 733,000 newly diagnosed invasive lung cancer cases in 2015 in China, and about 610,000 Chinese will die from lung cancer in 2015 [1]. The main reason for higher mortality is that most cases of lung cancer are diagnosed at an advanced stage. Nowadays, researchers agree that early diagnosis and individualized therapy are very important to improve survival and prognosis. Thus, development of new technology on diagnosis and therapy are greatly needed.
Stathmin is composed of 149 amino acids, which are organized into four domains (I-IV). The core region of stathmin (amino acids 42-126) is site for tubulin interaction with the additional requirement of either an N- or C-terminal extension [2]. Previous studies suggest that stathmin is overexpressed in some types of human malignancies [3-8]. And, high expression of stathmin can potentially promote cell proliferation, motility and metastasis of malignant tumors [4, 9-11]. However, the study on the expression of stathmin and its clinical significance in lung adenocarcinoma (LAC) is considerably limited. The aim of this study is to investigate the expression of stathmin in lung adenocarcinoma and evaluate the anticarcinogenic effects of stathmin silencing. 


\section{RESULTS}

\section{Expression of stathmin in cancer and normal tissues}

Stathmin was expressed in the cellular protoplasm, which was colored brown by immunohistochemistry (IHC) (Figures 1A, B, C, D, E, F, G, and 1H). Stathmin was highly expressed in $31(38.7 \%)$ of the 80 lung cancer tissues, whereas was lowly expressed in $12(15 \%)$ of the 80 normal tissues $(\mathrm{p}<0.05)$ (Table 1$)$. To further confirm these findings, the expression level of stathmin was detected in paired LAC tissue specimens by Western blot. As shown in Figure 2A, stathmin was overexpressed in cancerous tissues compared with normal tissues $(\mathrm{p}<0.05)$.

\section{Correlation between expression of stathmin and clinicopathologic factors of lung cancer}

Stathmin was overexpressed in lung adenocarcinoma (LAC) $(22 / 38,57.9 \%)$ compared with lung squamous cell carcinoma (LSCC) $(9 / 42,21.4 \%)(p<0.05)$. Poorly differentiated lung cancer tissues displayed a higher expression of stathmin $(62.1 \%)$ than well-differentiated tissues $(28.6 \%)(p<0.05)$. The expression of stathmin in cancer tissues without lymph node metastasis was $25 \%$, which is lower than those cases with lymphatic invasion as follows: N1, 53.3\%; N2, 70\%; and N3, 100\%, respectively $(\mathrm{p}<0.05)$. And increased stathmin was also observed in cancer tissues with stages III (68\%) and IV (75\%), compared with cases of stages I (both $0 \%)$ and II (24.2\%) $(\mathrm{p}<0.05)($ Table 1).

\section{Silencing of stathmin inhibited expression of stathmin}

Lung adenocarcinoma PC-9 cells were transfected by two different shRNAs (shRNA1 and shRNA2) targeting the stathmin gene. After $48 \mathrm{~h}$, we harvested the cells and detected the protein and mRNA levels of stathmin using RT-PCR and Western blot. Relative quantification analysis revealed that stathmin- specific shRNA (shRNA1) significantly down-regulated the expression of protein and mRNA of stathmin $(p<0.05)$ (Figure 2B, C and 2D). Therefore, the PC-9 cells that were transfected with shRNA1 (shRNA) was used to carry out following experiments. The following experiments were divided into three groups: blank, negative control (NC, non-specific to any known gene), and stathmin-specific shRNA.

\section{Silencing of stathmin decreased deformability of lung adenocarcinoma cells}

Transmission electron microscope (TEM) showed that stathmin silencing impeded the formability of
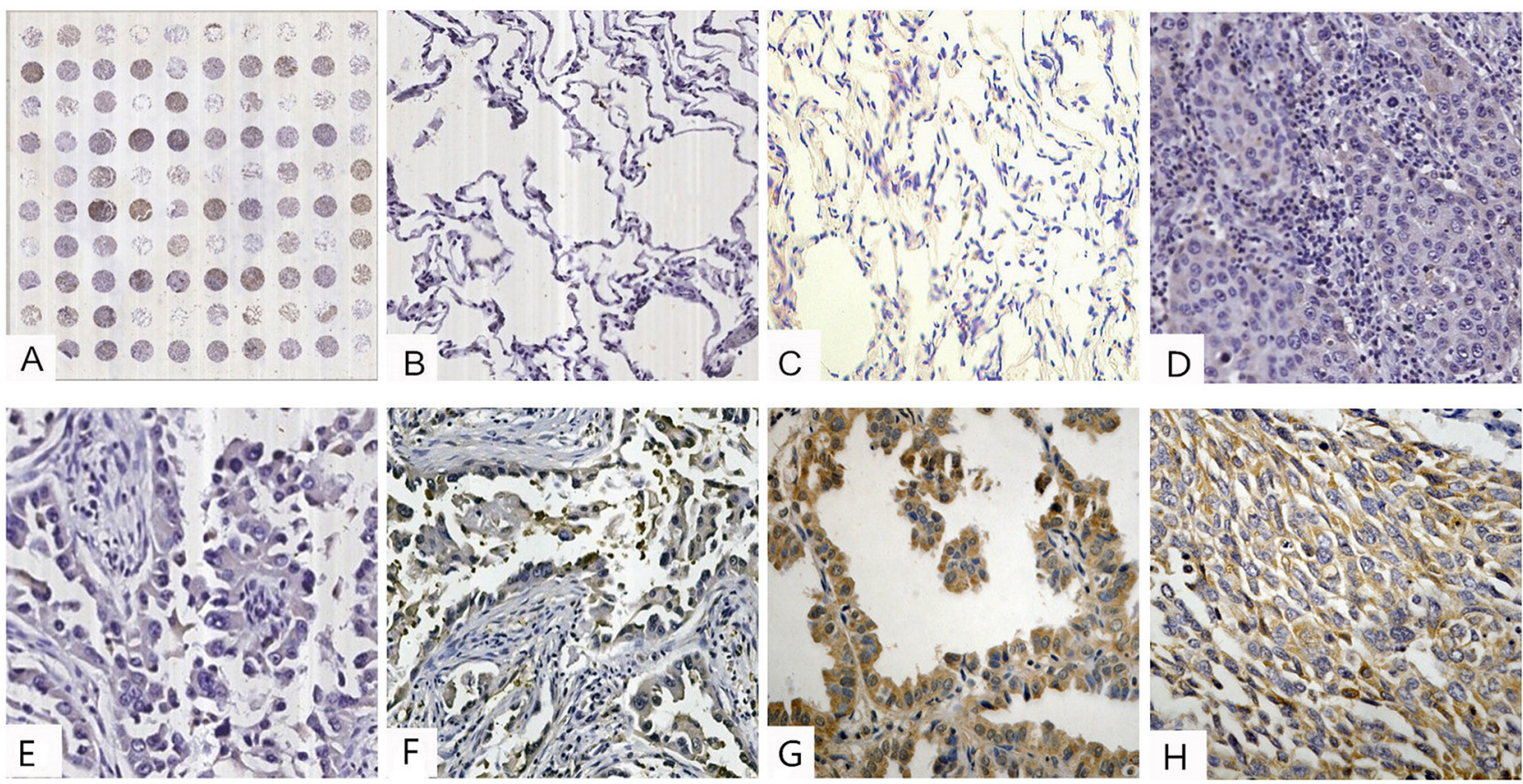

Figure 1: IHC analysis of stathmin in lung cancer and normal lung tissues $($ IHC $\times 400)$. A. tissue microarray construction; B. low staining of stathmin in normal lung tissues; C. moderate staining of stathmin in normal lung tissues; D. low staining of stathmin in well differentiated LSCC; E. low staining of stathmin in well differentiated LAC; F. moderate staining of stathmin in moderately differentiated LAC; G. high staining of stathmin in poorly differentiated LAC; H. moderate staining of stathmin in moderately differentiated LSCC; LAC, lung adenocarcinoma; LSCC, lung squamous cell carcinoma. 
Table 1: Correlation between clinico-pathological features and expressions of stathmin in lung cancer

\begin{tabular}{|c|c|c|c|c|c|c|c|}
\hline \multirow{2}{*}{ Parameter } & \multirow{2}{*}{ Group } & \multirow{2}{*}{$\mathbf{N}$} & \multicolumn{5}{|c|}{ Expression of Stathmin } \\
\hline & & & Low $(\%)$ & Moderate (\%) & High (\%) & $\chi^{2}$ value & $P$ value \\
\hline \multicolumn{8}{|l|}{ Item } \\
\hline & Normal & 80 & $50(62.5)$ & $18(22.5)$ & $12(15)^{\circledR}$ & \multirow{2}{*}{21.084} & \multirow{2}{*}{0.001} \\
\hline & Cancerous & 80 & $22(27.5)$ & $27(33.8)$ & $31(38.7)$ & & \\
\hline \multicolumn{8}{|l|}{ Gender } \\
\hline & Male & 66 & $18(27.3)$ & $22(33.3)$ & $26(39.4)$ & \multirow{2}{*}{0.067} & \multirow{2}{*}{0.967} \\
\hline & Female & 14 & $4(28.6)$ & $5(35.7)$ & $5(35.7)$ & & \\
\hline \multicolumn{8}{|l|}{ Ages } \\
\hline & $<60$ & 42 & $10(23.8)$ & $16(38.1)$ & $16(38.1)$ & \multirow{2}{*}{0.984} & \multirow{2}{*}{0.624} \\
\hline & $\geq 60$ & 38 & $12(31.6)$ & $11(28.9)$ & $15(39.5)$ & & \\
\hline \multicolumn{8}{|l|}{ Smoking } \\
\hline & 0 & 38 & $12(31.6)$ & $14(36.8)$ & $12(31.6)$ & \multirow{3}{*}{0.696} & \multirow{3}{*}{0.792} \\
\hline & $0.1-40$ & 12 & $3(25)$ & $4(41.7)$ & $5(33.3)$ & & \\
\hline & $>40$ & 30 & $7(23.3)$ & $9(30)$ & $14(46.7)$ & & \\
\hline \multicolumn{8}{|l|}{ Histology } \\
\hline & LAC & 38 & $4(10.5)$ & $12(31.6)$ & $22(57.9)^{\boldsymbol{\Delta}}$ & \multirow{2}{*}{14.53} & \multirow{2}{*}{0.001} \\
\hline & LSCC & 42 & $18(42.9)$ & $15(35.7)$ & $9(21.4)$ & & \\
\hline \multicolumn{8}{|c|}{ Pathological Grade } \\
\hline & Poorly & 29 & $5(17.2)$ & $6(20.7)$ & $18(62.1)^{\star}$ & \multirow{3}{*}{16.351} & \multirow{3}{*}{0.003} \\
\hline & Moderately & 30 & $7(23.3)$ & $16(53.3)$ & $7(23.3)$ & & \\
\hline & Well & 21 & $10(47.6)$ & $5(23.8)$ & $6(28.6)$ & & \\
\hline \multicolumn{8}{|c|}{ Lymphatic Invasion } \\
\hline & No & 52 & $19(36.5)$ & $20(38.5)$ & $13(25.0)^{\varpi}$ & \multirow{4}{*}{15.279} & \multirow{4}{*}{0.018} \\
\hline & $\mathrm{N} 1$ & 15 & $2(13.3)$ & $5(33.3)$ & $8(53.3)$ & & \\
\hline & $\mathrm{N} 2$ & 10 & $1(10)$ & $2(20)$ & $7(70)$ & & \\
\hline & N3 & 3 & $0(0)$ & $0(0)$ & $3(100)$ & & \\
\hline \multicolumn{8}{|l|}{ pTNM } \\
\hline & IB & 3 & $0(0)$ & $3(100)$ & $0(0)^{\bullet}$ & \multirow{4}{*}{15.194} & \multirow{4}{*}{0.019} \\
\hline & IIA-IIB & 33 & $14(42.4)$ & $11(33.3)$ & $8(24.2)^{\bullet}$ & & \\
\hline & IIIA-IIIB & 40 & $8(20)$ & $12(30)$ & $20(50)$ & & \\
\hline & IV & 4 & $0(0)$ & $1(25)$ & $3(75)$ & & \\
\hline
\end{tabular}

${ }^{\circledR} p=0.001$, normal tissues compared with cancerous tissues; ${ }^{\star}{ }^{\star} p=0.001$, LAC compared with LSCC; ${ }^{\star} p=0.003$, poorly differentiated tissues compared with moderately and well differentiated tissues; $p=0.018$, N0 compared with N1, N2, and N3, respectively; ${ }^{\bullet} p=0.019$, IB and IIA-IIB compared with IIIA-IIIB and IV, respectively; LAC, lung adenocarcinoma; LSCC, lung squamous cell carcinoma; Smoking, pack years of smoking. 
pseudopodia of PC-9 cells, and also weakened the deformability of lung adenocarcinoma PC-9 cells, which indicated that overexpression of stathmin promoted the mobility and migration of lung adenocarcinoma cells (Figure 2E).

\section{Silencing of stathmin suppressed proliferation of lung adenocarcinoma cells}

CCK8 analysis was employed to test the influence of shRNA-mediated stathmin silencing on proliferation of PC-9 cells. The results showed that silencing of stathmin significantly reduced proliferation of PC-9 cells $(1.08 \pm 0.79 \%)$ in a time-dependent manner (at 48, 72 and 96) (Figure $2 \mathrm{~F}, \mathrm{P}<0.05$ ), as compared with the blank

A

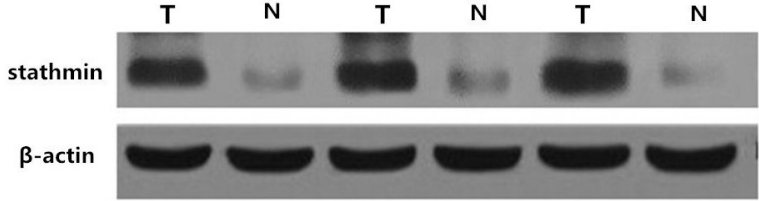

E

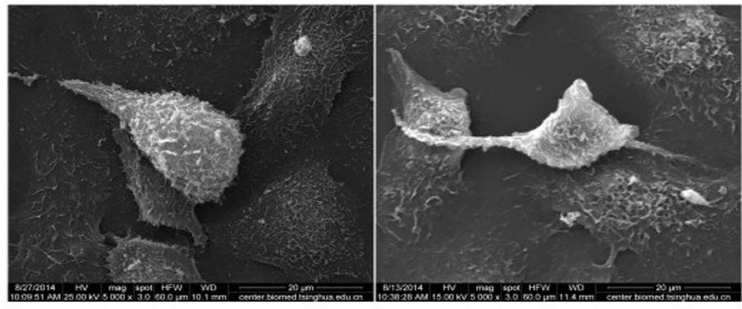
Blank

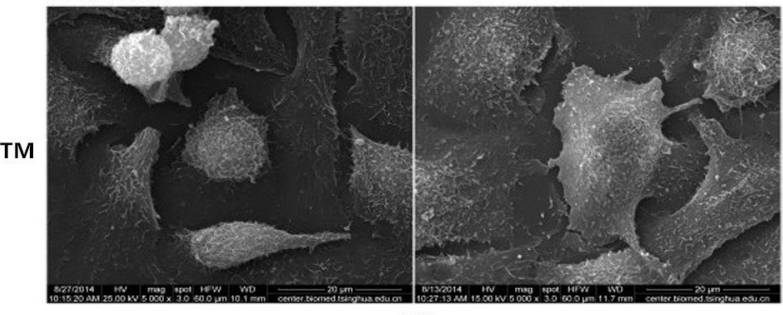

NC

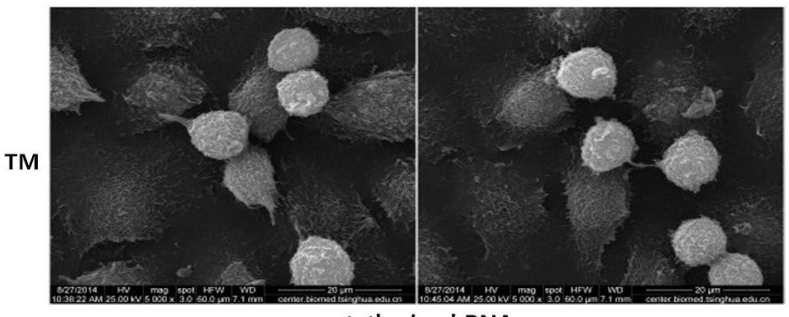

stathmin-shRNA
$(1.51 \pm 1.25 \%)$ and $\mathrm{NC}(1.45 \pm 1.19 \%)$ groups $(\mathrm{p}<0.05)$ (Table 2).

\section{Silencing of stathmin induced apoptosis of lung adenocarcinoma cells}

As shown in Figure 3A, TUNEL staining showed that silencing of stathmin induced apoptosis of lung adenocarcinoma cells, which showed following features: chromatic agglutination, karyopyknosis, nuclear fragmentation and brown granules. The apoptosis rate of PC-9 cells transfected with stathmin- shRNA $(11.67 \pm 2.08 \%)$ was remarkably higher than those in blank group $(2.67 \pm 1.53 \%)$ and NC group $(4.33 \pm 1.15 \%)(\mathrm{p}<0.05)$ (Figure 3B and Table 2).
B

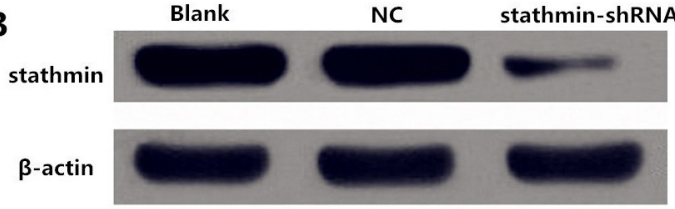

\section{C}

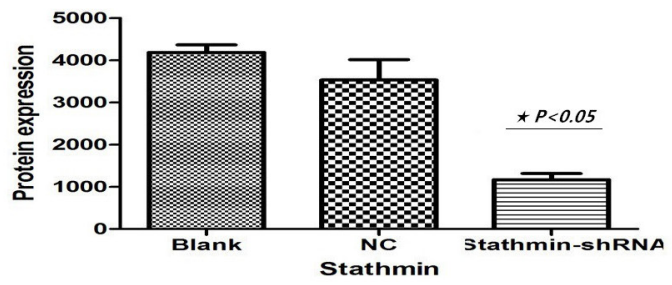

D

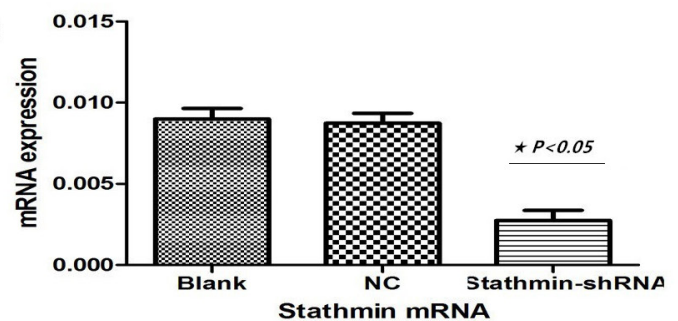

F

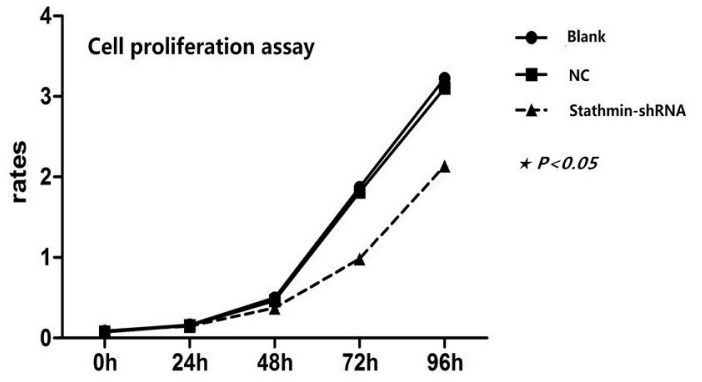

Figure 2: Efficacy of stathmin-shRNA in lung adenocarcinoma cells. A. western blot showed that stathmin was overexpressed in LAC tissues compared with normal lung tissues $(p<0.05)$; B-C. western blot showed stathmin-specific shRNA decreased the expression of stathmin $(p<0.05)$; D. real-time PCR showed that stathmin-specific shRNA decreased the expression of stathmin mRNA $(p<0.05)$; E. transmission electron microscopy showed that stathmin-specific shRNA weakened the deformability of PC-9 cells and reduced pseudopodia of PC-9 cells, as compared to the blank and NC groups; F. proliferation of PC-9 cells transfected with stathmin-shRNA was significantly decreased, as compared with the blank and NC groups; NC, lung adenocarcinoma PC-9 cells transfected with negative control shRNA; TEM, transmission electron microscopy. 


\section{Silencing of stathmin inhibited clone formation of lung adenocarcinoma cells}

Plate clone formation assay was employed to evaluate the influence of shRNA-mediated stathmin silencing on proliferation of PC-9 cells. As shown in Figure 3C, the clone number of PC-9 cells transfected with stathmin- shRNA (56.33 \pm 5.51$)$ significantly reduced, as compared with those in blank group (105.00 \pm 7.00$)$ and

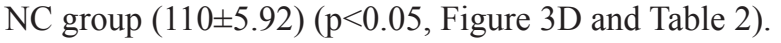

\section{Silencing of stathmin impeded adhesion of lung adenocarcinoma cells}

As shown in Figure 4A, the cell adhesion of stathmin- shRNA group $(57.32 \pm 9.53 \%)$ significantly

Table 2: Assay of proliferation, apoptosis, clone formation, adhesion ability and invasion of cells in vitro

\begin{tabular}{lccccc}
\hline Methods & $\begin{array}{c}\text { Cell Proliferation } \\
\mathbf{( \% )}\end{array}$ & $\begin{array}{c}\text { Apoptosis Rates } \\
\mathbf{( \% )}\end{array}$ & $\begin{array}{c}\text { Clone Formation } \\
\text { (numbers) }\end{array}$ & $\begin{array}{c}\text { Cell Adhesion } \\
\text { Rates (\%) }\end{array}$ & $\begin{array}{c}\text { Cell Invasion } \\
\text { Account } \\
\text { (numbers) }\end{array}$ \\
\hline Blank & $1.51 \pm 1.25$ & $2.67 \pm 1.53$ & $105.00 \pm 7.00$ & $98.28 \pm 2.27$ & $60.33 \pm 3.76$ \\
NC & $1.45 \pm 1.19$ & $4.33 \pm 1.15$ & $110 \pm 5.92$ & $96.36 \pm 15.62$ & $54.00 \pm 4.58$ \\
Stathmin- & $1.08 \pm 0.79^{\star}$ & $11.67 \pm 2.08^{\star}$ & $56.33 \pm 5.51^{\star}$ & $57.32 \pm 9.53^{\star}$ & $17.67 \pm 1.53^{\star}$ \\
shRNA & $\mathbf{p}<\mathbf{0 . 0 5}$ & $\mathbf{p}<\mathbf{0 . 0 5}$ & $\mathbf{p}<\mathbf{0 . 0 5}$ & $\mathbf{p}<\mathbf{0 . 0 5}$ & $\mathbf{p}<\mathbf{0 . 0 5}$ \\
P value &
\end{tabular}

NC, lung adenocarcinoma PC-9 cells transfected with negative control shRNA; ${ }^{\star}$, PC-9 stathmin- shRNA group compared with PC-9 NC group and PC-9 blank groups.
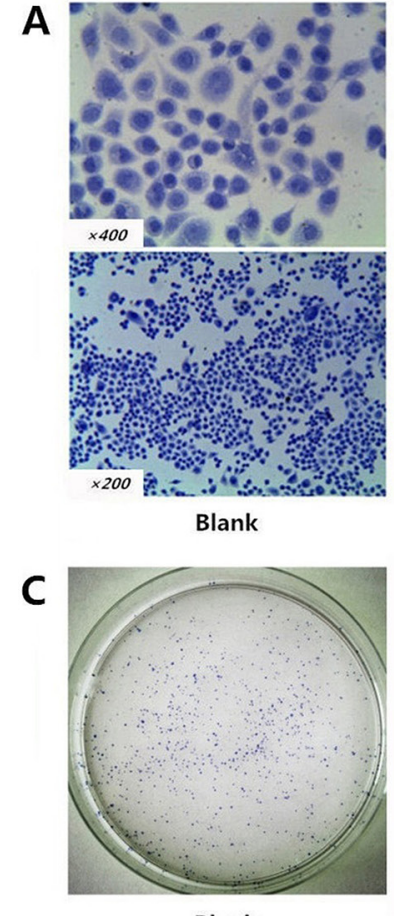

Blank

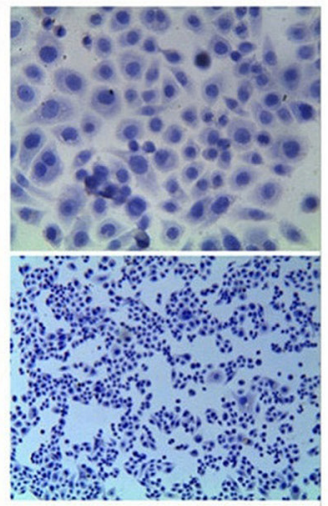

NC

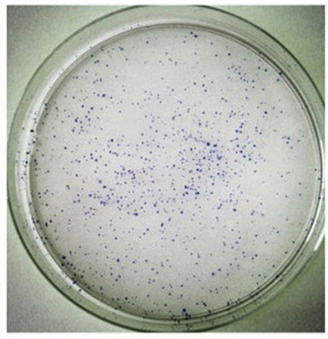

NC

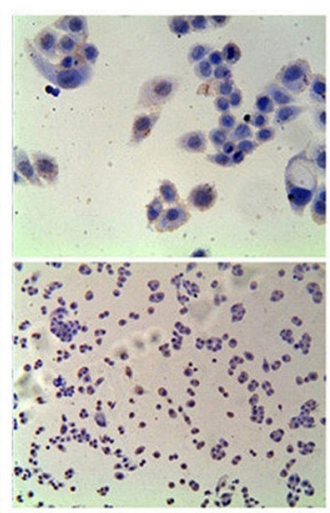

stathmin-shRNA

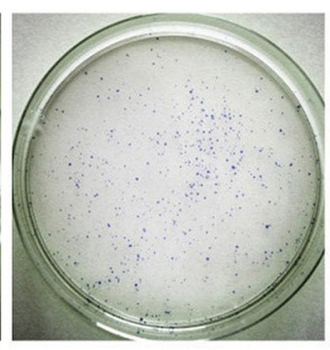

stathmin-shRNA
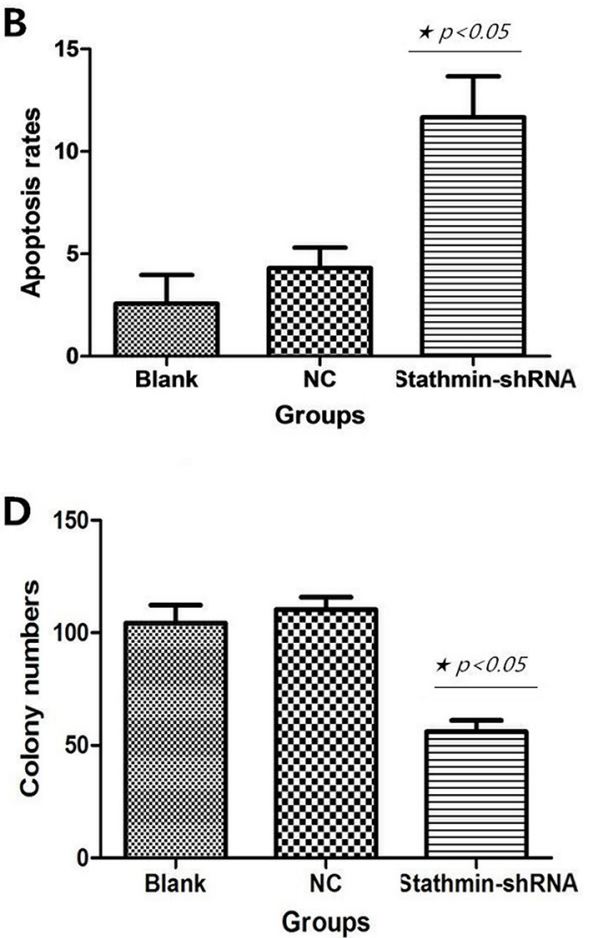

Figure 3: Effects of stathmin-specific shRNA on apoptosis and clone formation of PC-9 cells in vitro. A. positive cells were found by TUNEL staining: a shrinking cell body, nuclear pyrosis, chromatin condensation and tan or brown granules; B. cell apoptosis rate of the stathmin-specific shRNA group was obviously higher than those of the blank and NC groups $(\mathrm{p}<0.05)$; $\mathbf{C}$. the clone number of stathmin-specific shRNA group was less than blank and NC groups; D. the clone number of stathmin-specific shRNA group significantly was decreased, as compared to those of the blank and $\mathrm{NC}$ groups $(\mathrm{p}<0.05)$; NC, lung adenocarcinoma PC-9 cells transfected with negative control shRNA. 
reduced in a time-dependent manner (40 and $60 \mathrm{~min}$ ), as compared with the blank $(98.28 \pm 2.27 \%)$ and $\mathrm{NC}$ $(96.36 \pm 15.62 \%)$ groups respectively (Figure 4B and Table 2). This result suggested that overexpression of stathmin promoted the mobility and migration of lung adenocarcinoma cells.

\section{Silencing of stathmin blocked invasion of lung adenocarcinoma cells}

As shown in Figure 4C, Transwell assay revealed that the invasion number of stathmin- shRNA (17.67 \pm 1.53$)$ group was remarkably decreased compared with the blank $(60.33 \pm 3.76)$ and $\mathrm{NC}(54.00 \pm 4.58)$ groups $(p<0.05)$ (Figure 4D and Table 2), which suggested that downregulation of stathmin blocked the mobility and migration of lung adenocarcinoma cells.

\section{Anticarcinogenic efficacy of stathmin silencing may be involved in P38 and MMP2 signal pathways}

As shown in Figures 5A and 5B, stathmin silencing led to the mRNA downregulation of P38 and MMP2 in lung adenocarcinoma PC-9 cells $(\mathrm{p}<0.05)$. And Western Blot displayed that stathmin silencing downregulated the protein expressions of P38, phosphorylated P38 and MMP2 (Figures 5C and 5D) $(\mathrm{p}<0.05)$, suggesting that anticarcinogenic efficacy of stathmin silencing may be involved in P38 and MMP2 signal pathways.

\section{Silencing of stathmin retarded growth of transplantation tumors}

Compared with the blank $\left(2028.33 \mathrm{~mm}^{3}\right)$ and NC $\left(2147.9801 \mathrm{~mm}^{3}\right)$ groups, the xenografted tumors of the stathmin-specific shRNA group had a slower growth velocity $\left(1137.943 \mathrm{~mm}^{3}\right.$ ) (Table 3 and Figure $5 \mathrm{E}$ ). In particular, xenografted tumors of the stathminspecific shRNA group had an earlier burst, ulceration and adjacent diffusion (Figure 6A). In addition, the sizes of xenografted tumors resected from nude mice of stathminspecific shRNA group were remarkably smaller than those from blank and NC groups, and in vivo imaging of nude mice displayed a consistent trend (Figure 6B). Get together, silencing of stathmin retarded the growth of transplantation tumors in nude mice.

\section{Silencing of stathmin suppressed metastasis of transplantation tumors in nude mice}

The xenografted tumors from PC-9 cells appeared liver and lung metastasis of nude mice in our study. Imaging detecting showed that the lung and liver of stathmin-specific shRNA group displayed an lower luminescence than those in blank and NC groups, suggesting that anti-stathmin treatment prevented metastasis of liver and lung metastasis (Figure 6B). Meanwhile, the expression of stathmin in tumor tissues from the nude mice of stathmin-specific shRNA group was lower than in those in blank and NC groups $(\mathrm{p}<0.05)$, thus
A

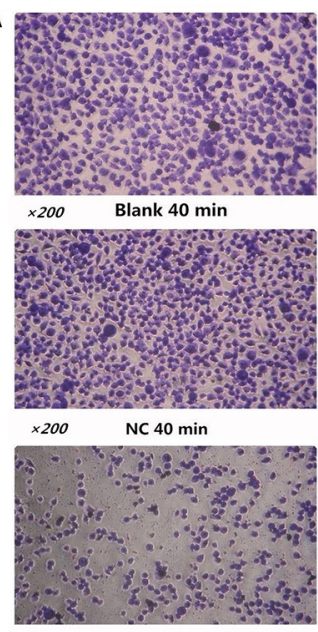

$\times 200$ Stathmin-shRNA $40 \mathrm{~min}$

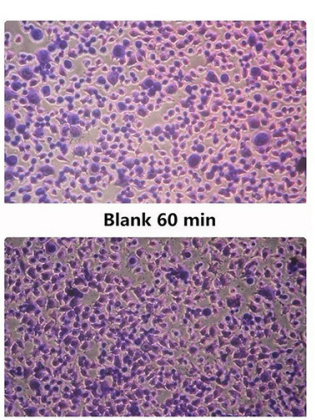

NC $60 \mathrm{~min}$

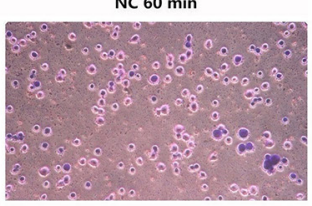

Stathmin-shRNA $60 \mathrm{~min}$
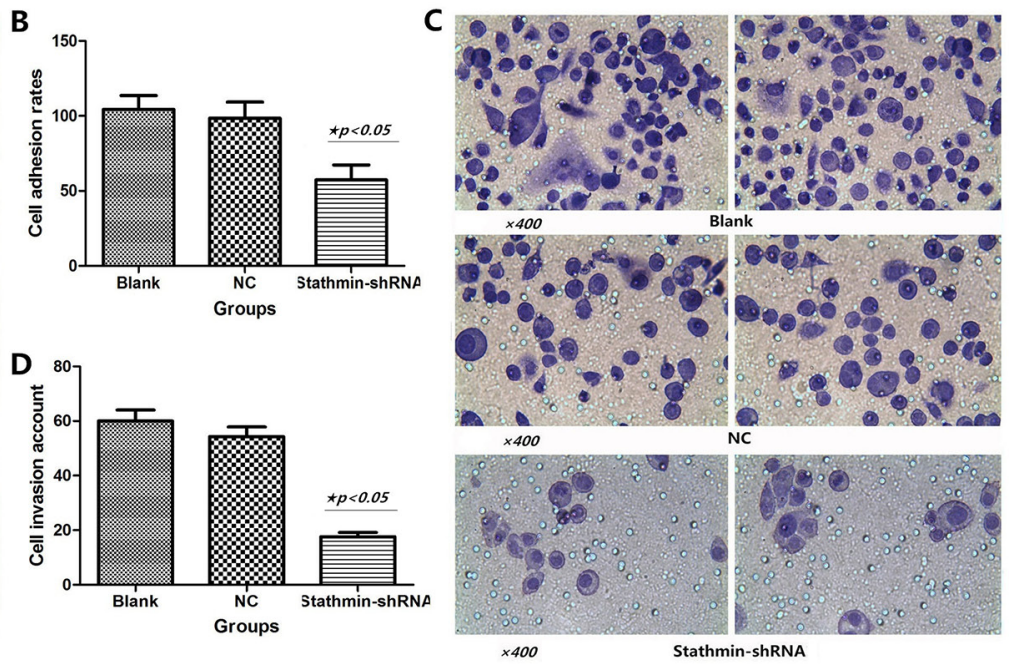

Figure 4: Effects of stathmin-specific shRNA on adhesion and invasion of PC-9 cells in vitro. A. cell adhesion ability of stathmin- shRNA group significantly reduced in a time-dependent manner (40min and 60min), as compared with the blank and normal control groups; B. cell adhesion rate of stathmin- shRNA group was lower than those of the blank and NC groups ( $<<0.05$ ); C. transwell assay revealed that invasion of stathmin- shRNA group significantly reduced compared with the blank and NC groups ( $<<0.05$ ); $\mathbf{D}$. cell invasion number of shRNA group was less than the those of blank and NC groups $(p<0.05)$; NC, lung adenocarcinoma PC-9 cells transfected with negative control shRNA. 
confirming that this anticarcinogenic efficacy correlated with the silencing of stathmin (Figure 6C).

\section{DISCUSSION}

Stathmin (also known as Op18, p18, p19, or metablastin), a 19-kDa soluble phosphoprotein, is upregulated in some cancers and relates to cell differentiation and proliferation [3-6, 9]. The overexpression of stathmin may activate biological behavior of cancers whereas the inhibition of stathmin expression can interfere with proliferation in cancer cells, inhibiting tumor malignant behavior [4, 9]. A variety of target-specific anti-stathmin investigations have been demonstrated to reduce cell proliferation, clonal growth, cell motility, metastasis and increase apoptosis in malignant tumors $[9,12]$.

To clarify the stathmin expression in lung cancer, we performed a test of IHC on tissue microarray (TMA). The results showed that $57.9 \%$ of LAC presented a higher expression of stathmin, which indicated that overexpression of stathmin may be particularly related to the malignant behavior of LAC. We also noticed that high expression of stathmin was positively associated with poorly differentiated, lymph node invasion and advanced TNM stage in LAC, which suggested that stathmin has the potential to be a prognostic marker for LAC. Our findings are consistent with previous some investigations, where overexpression of stathmin in cancers is associated with a poor prognosis $[5,9,12-15]$. Some studies reported that abnormal expression of stathmin could lead to the dysfunction of microtubule assembly and disorder of cell cycles regulation $[9,12,14,15]$. And, stathmin has already been found to be involved in the oncogenesis of a wide variety of human cancers $[3-5,7,9,10,12,15,16]$. Thus, this is possibility that overexpression of stathmin may potentially promote oncogenesis and development of LAC, which contributes to cell proliferation, motility and metastasis of LAC.

We found that stathmin silencing of LAC PC-9 cells transfected with stathmin-specific shRNA significantly surpressed the proliferation, adhesive and invasiveness of PC-9 cells, indicated that overexpression of stathmin promoted the proliferation, migration and invasion of LAC. Previously, a variety of target-specific anti-stathmin investigations have been demonstrated to reduce cell proliferation, clonal growth, cell motility and metastasis $[4,17,18]$. Several studies suggest that there is a intimate correlation between stathmin expression and cell-cycle regulation. Knockdown of stathmin lead to cell cycle arrest in $\mathrm{G} 2 / \mathrm{M}$ phase, thus reduces the viability, colony formation and cell proliferation $[9,12,15,19]$. Stathmin
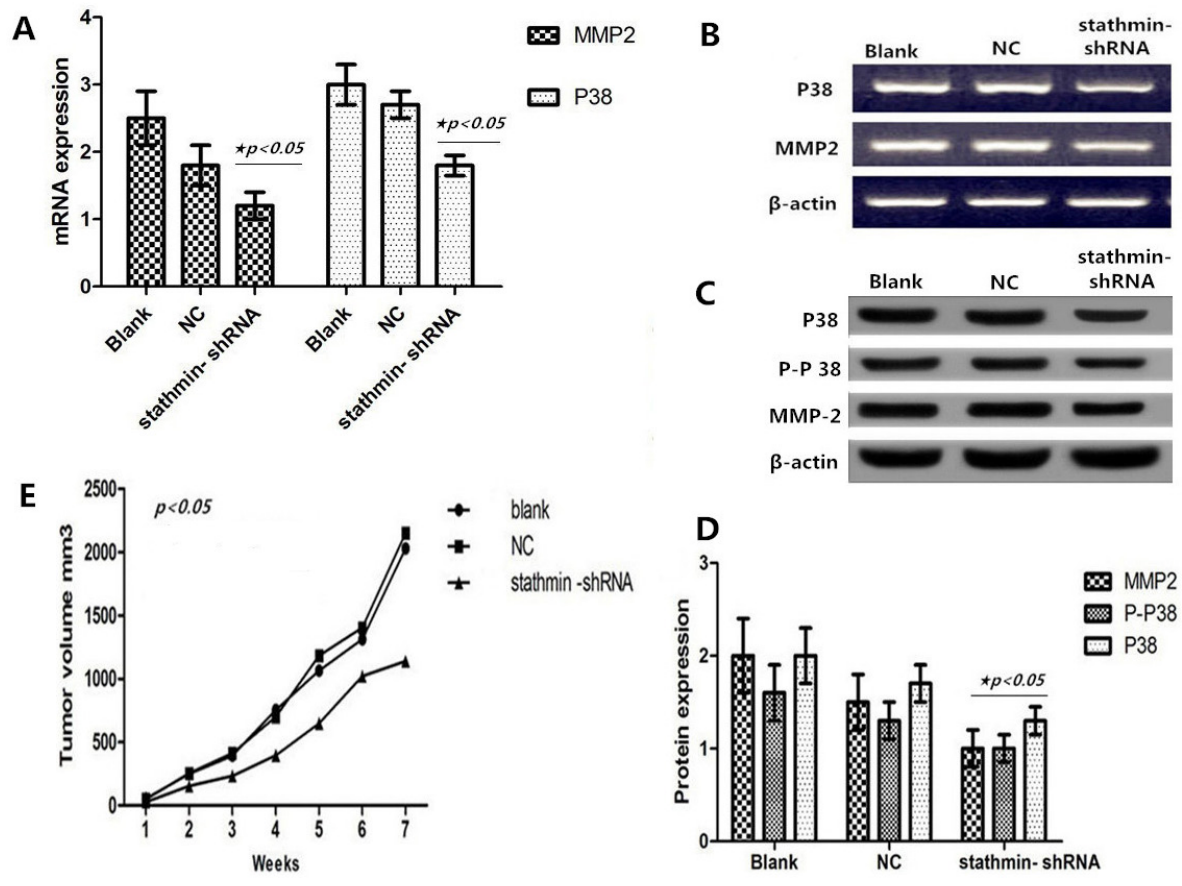

Figure 5: Effect of stathmin silencing on the P38 signally pathway in vitro. A. silencing of stathmin reduced the mRNA expressions of P38 and MMP2 in PC-9 cells ( $<0.05)$; B. mRNA expressions of P38 and MMP2 in RNAi group were less than in blank and NC groups; C-D. western blot showed that protein expressions of P38, phosphorylated P38 and MMP2 were downregulated in stathminshRNA group compared with the blank and NC groups $(\mathrm{p}<0.05)$; E. the growth of transplantation tumors in blank and NC groups were relatively quick compared with the stathmin- shRNA group $(\mathrm{p}<0.05)$; NC, lung adenocarcinoma PC-9 cells transfected with negative control shRNA. 
Table 3: Growth trend of transplantation tumors in nude mice

\begin{tabular}{lccc}
\hline \multirow{2}{*}{ Time (weeks) } & \multicolumn{3}{c}{ Overall volume $\left(\mathbf{m m}^{\mathbf{3}}\right)$} \\
\cline { 2 - 4 } & Blank & NC & Stathmin-shRNA \\
\hline 1 & 54.10879 & 49.2356 & 26.99287 \\
3 & 249.2315 & 253.1536 & 152.9214 \\
4 & 391.9232 & 411.4478 & 233.215 \\
5 & 753.2844 & 699.3681 & 394.3699 \\
6 & 1062.61 & 1181.7722 & 646.8466 \\
7 & 1312.047 & 1403.3368 & 1020.638 \\
Overall & 2028.33 & 2147.9801 & $1137.943{ }^{\star}$ \\
P value & 5851.54 & 6146.294 & $3634.927 \star$ \\
\hline
\end{tabular}

NC, lung adenocarcinoma PC-9 cells transfected with negative control shRNA; ${ }^{\star}$, PC-9 stathmin-shRNA group compared with PC-9 NC and blank groups.
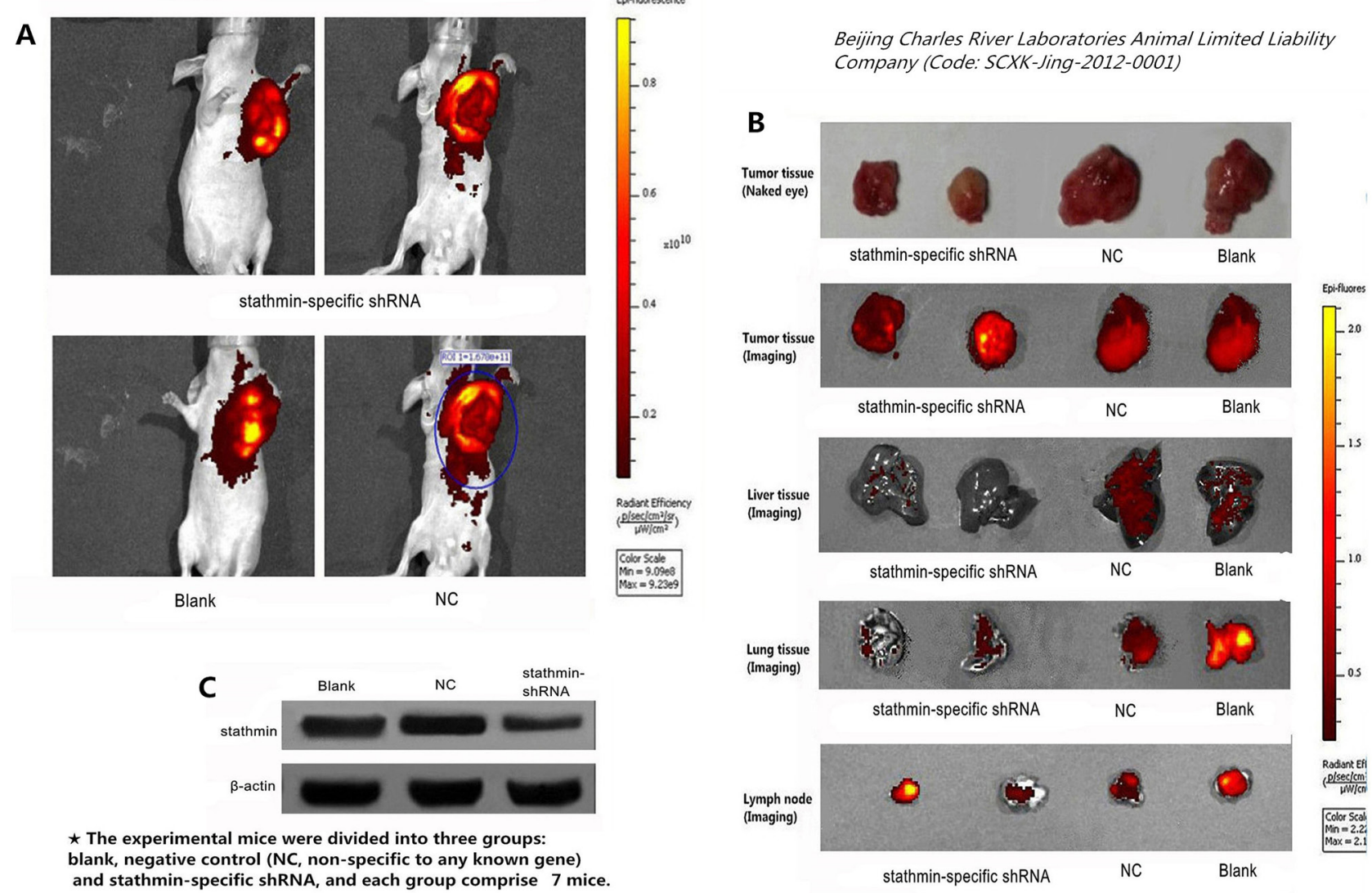

Figure 6: Effect of stathmin silencing on transplantation tumors growth in nude mice. A. compared with the stathminspecific shRNA group, the tumors of blank and NC groups had a higher luminescence than those in stathmin-specific shRNA group; B. separated tumors from nude mice of stathmin-specific shRNA group were less than those in the blank and NC groups and stathmin silencing prevented metastasis of lung and liver, as well as lymph node metastasis; C. stathmin expression in transplantation tumors of stathminspecific shRNA group was higher than in blank and NC groups $(\mathrm{p}<0.05)$; NC, lung adenocarcinoma PC-9 cells transfected with negative control shRNA. 
is the important member of a family of microtubuledestabilizing proteins [20], has been showed participating the transcriptional and post-transcriptional regulation of cell cycle progression [9]. We observed that silencing of stathmin induced apoptosis of PC-9 cells, which suggested that stathmin overexpression could increase the progression of LAC via apoptosis inhibition mechanism. Previous studies demonstrate that stathmin present an antiapoptotic activity to prompt the progress of tumor cells and play an important role in the control of cell cycle [17, 18, 21-23]. Excitedly, we also found that pseudopodia of PC-9 cells transfected with stathmin-specific shRNA significantly reduced and cell deformation ability decreased, expounding that treatment of anti-stathmin could suppress cell movement and invation. Supporting evidence also reports in gastic cancer, in which movement invasion of cells was effectively suppressed by stathmin silencing in the Matrigel invasion assay [10].

Previous investigation shows that stathmin not only plays an important role in cell proliferation and motility but also participates as a "relay protein" in several intracellular cancer related signaling pathways, such as the Hedgehog signaling pathway [24], p53 pathway [16] and Pak1-WAVE2-kinesin complex [25]. Although many studies have identified that stathmin is involved in the activation and inactivation of motility in tumor pathological process $[6,12,15-18,23]$, much still has not be disclosed pertaining the molecular signally pathways how stathmin performs the role. We found that silencing of stathmin incurred the reduction of the relevant proteins of P38-MAPK signal pathway including P38, phosphorylated P38 and MMP2, suggesting that the anticarcinogenic efficacy of stathmin silencing might be involved in P38 signaling pathways. One study has identified stathmin as a specific target of apoptosis signal-regulating kinase 1 (ASK1)-p38 cascade [26], and stathmin can increase cell migration via cooperative activation of p38 [27]. Overexpression of MMP2 has been found to be involved in the tumorigenesis, progression and prognosis of some cancers [28, 29]. Our findings showed that stathmin silencing decreased expression of MMP2, suggesting that stathmin might promote the proliferation and invasion of LAC via upregulating the expression of MMP2.

The anticarcinogenic efficacy of stathmin knockdown on the growth and metastasis of implanted cancer in nude mice have been proved in some previous studies $[4,9,10,30]$. We demonstrated that not only the volumes of transplantation tumors and the numbers of lung and liver metastatic reduced in the nude mice after stathmin-shRNA treatment, but lymphatic metastasis also significantly abated, which strongly suggested that silencing of stathmin exerted the anti-proliferation and anti-metastasis effect on LAC. Nowadays, many kinds of target-specific anti-stathmin effectors, including ribozymes, monoclonal antibody, shRNA and siRNA have been used extensively to decrease the expression of stathmin in vitro and vivo to investigate the therapeutic strategies targeted towards stathmin $[4,7,9,10,12,15$, $23,30,31]$. In human cancer, stathmin is usually overexpressed, and decrease the expression of stathmin in vitro and vivo always significantly reduce cell proliferation, clonal growth, cell motility, metastasis and increased apoptosis $[4,7,9,10,12,15,30]$. Together, it is very possible that an'anti-stathmin' targeted therapy could provide a reliable strategy to specifically impede tumor proliferation, motility, migration and occurence of metastasis.

\section{MATERIALS AND METHODS}

\section{Culture of cell lines}

Lung adenocarcinoma PC-9 cells were purchased from Fuxiang Cell Biology Limited Company, Shanghai, China. The cells were cultured in an RPMI 1640 medium, which included $10 \% \mathrm{FBS}, 100$ units $/ \mathrm{mL}$ penicillin, and $100 \mu \mathrm{g} / \mathrm{mL}$ streptomycin (Invitrogen). We maintained the culture solution at $37^{\circ} \mathrm{C}$ with a humidified $5 \% \mathrm{CO}_{2}$ and $95 \%$ air incubator. When the cells grew into a logarithmic phase, we harvested the cells and carried out a series of following investigations.

\section{BALB/c nude mice}

Twenty-eight female BALB/c nude mice aged 4-6 weeks obtained from Beijing Charles River Laboratories Animal Limited Liability Company (Code: SCXKJing-2012-0001). The nude mice were fed and raised separately under specific-pathogen free (SPF) conditions in the Centre of Animal Studies of Xi'an Jiaotong University. We strictly controlled the living conditions as follows: temperature ranged from 20 to $22{ }^{\circ} \mathrm{C}$; humidity ranged from $40 \%$ to $60 \%$; and artificial illumination was regulated as a light/dark cycle per $12 \mathrm{~h}$. The Beijing Medical Experimental Animal Care Commission approved the experimental protocol and followed by institutional review board guidelines.

\section{Patients}

We collected 80 lung cancer tissues from primary lung cancer patients who underwent surgical resection of tumors at the Second Affiliated Hospital, Xi'an Jiaotong University, Shaanxi, China. We obtained written and informed consent individually from all the patients. The study was approved by the Research Ethics Committee of Second Affiliated Hospital, Xi'an Jiaotong University, Shaanxi, China. The patients with lung cancer were divided into different groups according to different clinical features [32] (Table 1). In addition, we also collected 80 matched adjacent normal tissues as the normal control, which were separated from the edge of tumor mass at least $3 \mathrm{~cm}$ away. 


\section{Pathological study and tissue microarray construction}

In order to construct TMA, we invited two pathologists to discern and mark representative tumor areas. TMA was constructed according to a method previously described [33, 34] using Manual Tissue Arrayer (Beecher Instruments, USA). The constructed TMA block was sliced and kept in refrigerator at $4{ }^{\circ} \mathrm{C}$, and further tested with H\&E staining and IHC.

\section{IHC}

IHC was employed to determine the expression of stathmin in tissues (S-P Kit, product code: SP9000, Zhongshan Jinqiao Biotech Company, Beijing, China) according to a method previously described [33] (antistathmin antibody, 1:200 dilution, Abcam Company). The positive control was stathmin-positive slices provided by biological company, and PBS as a replacement was used as the negative internal control. Two pathologists blindly evaluated the immunostaining scores according to a method previously described [33].

\section{Western blot}

Western blot was employed to disclose the expression status of proteins according to a method previously described [33] (anti- stathmin 1:800; antiMMP2 1:1000, Abcam Company; anti- p38 MAPK 1:1000, Abcam Company; Phospho-p38 MAPK Antibody 1:1000, BioVision Inc.). We used $\beta$-actin as the internal control.

\section{Real-time quantitative PCR}

We used RNA simple total-RNA kit (Tiangen Biotech, Beijing, China) to isolate total RNA, and also performed a real-time quantitative PCR (RTPCR) using SYBR Green (Tiangen Biotech, Beijing, China) according to the manufacturer's instructions. The conditions of amplification: pre-incubation at $94{ }^{\circ} \mathrm{C}$ for $6 \mathrm{~min} ; 38$ cycles at $95{ }^{\circ} \mathrm{C}$ for $5 \mathrm{~s} ; 7^{\circ} \mathrm{C}$ for $45 \mathrm{~s}$; and $72{ }^{\circ} \mathrm{C}$ for $30 \mathrm{~s}$. We analysed the quantity of mRNA using the $2^{-\Delta \Delta \mathrm{Ct}}$ method and $\beta$-actin served as the internal control. Primer sequences of mRNA for detection targets in this study are as follows: $\beta$-actin forward 5'-ATCATGTTTGAGACCTTCAACA-3'; reverse 5'-CATCTCTTGCTCGAAGTCCA-3'; stathmin forward 5'-GAGAAACGAGAGCACGA-3'; reverse 5'-ATTTAGGAAGGGGATGG-3'; P38 forward 5'-CAT TACTTACATCACATGCTACAAA-3'; reverse 5'-ATG ACAGGGCTCAGCAGACT-3; MMP2 forward 5'-GATG CCGCCTTTAACTGG-3'; reverse 5'-TCAGCAGCCT AGCCAGTCG-3.

\section{RNA interference treatment of stathmin}

We searched for the gene sequences of stathmin from the GeneBank (MedLine, USA) and designed the oligonucleotide sequences using Vector NTI 11.5. And we performed a BLAST search of human genome database to assure that the synthesized oligonucleotide sequences would not target other gene transcripts. Finally, stathmin short hairpin RNA (shRNA) and non-specific shRNA were structured and introduced into cell PC-9 cell lines in Beijing Dingguo Changsheng biotechnology CO.LTD. The constructed sequences usd in this study are as follows: Sense chain: 5'-GATCC-(GN18)-(TTCAAGAGA)(N18C)-TTTTTTG-3'; Antisense chain: 3'-G(CN18)(AAGTTCTCT)-(N18G)-AAAAAACTTAA-5'; Sistathmin: TTATTAACCATTCAAGTCC; Sense chain: GATCCGTTATTAACCATTCAAGTCCTTCAAGAGA GGACTTGAATGGTTAATAACTTTTTTG; antisense chain: AATTCAAAAAAGTTATTAACCATTCAAGTC CTCTCTTGAAGGACTTGAATGGTTAATAACG; NC: 5'-TTCTCCGAACGTGTCACGT-3' 5'GATCCGTTCTC CGAACGTGTCACGTTTCAAGAGAACGTGACACGT TCGGAGAACTTTTTTG-3' 5'AATTCAAAAAAGTTC TCCGAACGTGTCACGTTCTCTTGAAACGTGACAC GTTCGGAGAACG-3'.

\section{Cell transfection}

We used Lipofectamine 2000 (Invitrogen) to do the transfection of shRNA according to the manufacturer's instructions. Briefly, the PC-9 cells were seeded at a concentration of $2 \times 10^{5}$ cells/well in a six-well plate and incubated until $\sim 80 \%$ confluence. Then, the Lipofectamine 2000 (Invitrogen) and shRNA were mixed gently and incubated together in Opti-MEM I at room temperature for $20 \mathrm{~min}$. Subsequently, the PC-9 cells were incubated in the shRNA-Lipofectamine complex-containing medium for $48 \mathrm{~h}$, and then harvested for further assays. The experiments were divided into three groups: blank, negative control (NC, non-specific to any known gene), and stathmin-specific shRNA.

\section{Transmission electron microscopy (TEM)}

Briefly, we washed PC-9 cells with PBS for twice, and added $25 \mathrm{ml} / 1$ glutaraldehyde to fix cells for $30 \mathrm{~min}$. Then, we used $10 \mathrm{~g} / \mathrm{l}$ osmic acid to fix the cells for $1 \mathrm{~h}$. Subsequently, we placed the cells in acetone for gradient dehydration and for displacement in embedding medium (1:1) for $30 \mathrm{~min}$. After $2 \mathrm{~h}$ in embedding reagents, we observed morphology and structure of cells under TEM.

\section{Cell proliferation assay}

We employed the Cell Counting Kit- 8 solution to perform proliferation assay of cells according to manufacturer's instructions. Briefly, PC-9 cells were 
seeded in 96-well culture plates at a density of $1 \times 10^{5}$ cells/100 ml/well, and then added $10 \mathrm{ml} /$ well of the Cell counting Kit-8 solution and incubated for $4 \mathrm{~h}$ [5]. After that, we used a microplate reader to measure the optical density of the well.

\section{TUNEL staining}

When PC-9 cells grew on glass coverslips, we used $4 \%$ paraformaldehyde to fix the cells at least for $30 \mathrm{~min}$. Next, we added $50 \mathrm{ul}$ of $0.1 \%$ Tritons X-100 to the cells and incubated at room temperature for $20 \mathrm{~min}$. Then the cells were treated using TUNEL kit (11684817910, Roche) according to the manufacturer's instructions. We adopted the following formula to calculate the apoptotic index: apoptotic index $=$ (total number of apoptotic cells/ total number of cells) $\times 100 \%$.

\section{Colony formation assay}

Briefly, 0.5\% agar (Sigma) was added in $60 \mathrm{~mm}$ dishes, then the treated PC-9 cells were digested into single cell suspension. PC-9 cells were mixed with $0.3 \%$ soft agar and added on the bottom agar with $2 \times 10^{3}$ cells per dish respectively. After that, we observed the cell clone formation under microscope. It was advisable that the cell clone formation was seen but not connected. Subsequently, we washed the cells twice with PBS, fixed with $4 \%$ paraformaldehyde for $20 \mathrm{~min}$, and stained with Giemsa solution for $15 \mathrm{~min}$. We counted the number of colonies under microscope.

\section{Matrigel invasion assay}

Briefly, Matrigel basement membrane (BD Biosciences, USA) were dissolved in the ice bath overnight. Next day, the matrigel basement membrane were diluted by MEM 1:100. And 300ul of matrigel basement membrane were added to the each well and embedded overnight. After that, PC-9 cells were trypsinized into single cell suspension, and were seeded in 24-well culture plates at a density of $1 \times 10^{5}$ cells/ well. Then we observed the cells at 20,40 and 60min, and removed the non-adherent cells respectively. Subsequently, we washed the cells twice with PBS, fixed with $4 \%$ paraformaldehyde for $20 \mathrm{~min}$, and stained with Giemsa solution for $15 \mathrm{~min}$, then counted the adherent rate and photographed.

\section{Cell migration assay}

Briefly, PC-9 cells were trypsinized into single cell suspension, and were seeded in a 24-well transwell chamber (3428, Corning, NY, USA) at a density of $1 \times 10^{5}$ cells/well, which were incubated for $48 \mathrm{~h}$ at $37^{\circ} \mathrm{C}$ in constant temperature and humidity incubator. After that, transmemberane were fixed with $4 \%$ paraformaldehyde for $20 \mathrm{~min}$, and were washed for 3 times with PBS. Subsequently, we added 50 ul of $0.1 \%$ Tritons X-100 to the cells, and counterstained with hematoxylin.

\section{Establishment of the transplantation tumor in node mice}

The 28 nude mice models were divided into three experimental groups: blank, NC and stathmin- shRNA. The lung adenocarcinoma PC-9 cells were transplanted via subcutaneous injection of $5 \times 10^{7}$ cells into the left flank of each nude mouse respectively. One week after transplantation, tumors had grown to a volume of approximately $20 \mathrm{~mm}^{3}$, which indicated that the model establishment succeeded. Eventually, a total of 21 nude mice ( 7 nude mice each group) are qualified to be included for statistical analysis.

\section{Calculation and observation of transplantation tumor}

The volume and size of a tumor was measured calculated according to a calculated standard previously described [19]. The computing formula is as follows: tumor volume $\left(\mathrm{mm}^{3}\right) \mathrm{V}=(\mathrm{a} 2 \times \mathrm{b}) / 2$, where $\mathrm{a}=$ the shortest diameter and $b=$ the longest diameter of the tumor (in $\mathrm{mm}$ ), forming the tumorgrowth curve.

\section{Vivo imaging observation of model mice}

Two mongths after inoculation, the situation of tumor growth and metastasis were searched in node mice by non-invasive optical imaging that was activated by tumor-specific luciferase. Briefly, experimental mice were injected by luciferase substrate luciferin $(150 \mathrm{mg} /$ $\mathrm{kg}$ ) while anesthetized by $2 \%$ isoflurane. The signal intensity on transplantation tumor of nude mice was detected using Living Image 4.0 (PerkinElmer, Alameda, CA, USA). The concrete quantity at the selected region of interest covering the tumor were identified by peak photon flux.

\section{Statistical analysis}

We used SPSS 22.0 software package (SPSS Institute, Chicago, USA) to make a statistical analysis. The enumeration data pertaining to stathmin expression and clinico-pathological features were calculated using the $\chi^{2}$ and Fisher's exact test. The data belonged to continual variables (mean \pm SEM) was analysed using the Student's T-test, and One-WAY ANOVA Test. All tests were two-sided, and p-values $<0.05$ were considered to be statistically significant. 


\section{ACKNOWLEDGMENTS AND FUNDING}

This study was supported by grants from the National Natural Scientific Foundation of China (No. $81172234)$, Project of science and technology project of Shaanxi Province (2013-K12-08-04) and Program for Changjiang Scholars and Innovative Research Team of China (PSCIRT:1171). We are grateful for the technical advice provided by Wang Jinsui (The People's Hospital of Gansu province, Lanzhou, Gansu, China) and Li Jun (The fourth Military Medical University, Xi'an, Shanxi, China).

\section{CONFLICTS OF INTEREST}

The authors declare no conflicts of interest.

\section{REFERENCES}

1. Chen W, Zheng R, Baade PD, Zhang S, Zeng H, Bray F, Jemal A, Yu XQ and He J. Cancer statistics in China, 2015. CA Cancer J Clin. 2016; 66:115-132.

2. Lachkar S, Lebois M, Steinmetz MO, Guichet A, Lal N, Curmi PA, Sobel A and Ozon S. Drosophila stathmins bind tubulin heterodimers with high and variable stoichiometries. J Biol Chem. 2010; 285:11667-11680.

3. Novak M, Lester J, Karst AM, Parkash V, Hirsch MS, Crum CP, Karlan BY and Drapkin R. Stathmin 1 and p16(INK4A) are sensitive adjunct biomarkers for serous tubal intraepithelial carcinoma. Gynecol Oncol. 2015; 139:104-111.

4. Liu X, Liu H, Liang J, Yin B, Xiao J, Li J, Feng D and Li Y. Stathmin is a potential molecular marker and target for the treatment of gastric cancer. Int J Clin Exp Med. 2015; 8:6502-6509.

5. Nie W, Xu MD, Gan L, Huang H, Xiu Q and Li B. Overexpression of stathmin 1 is a poor prognostic biomarker in non-small cell lung cancer. Lab Invest. 2015; 95:56-64.

6. Schimmack S, Taylor A, Lawrence B, Schmitz-Winnenthal H, Fischer L, Buchler MW, Modlin IM, Kidd M and Tang LH. Stathmin in pancreatic neuroendocrine neoplasms: a marker of proliferation and PI3K signaling. Tumour Biol. 2015; 36:399-408.

7. Kouzu Y, Uzawa K, Koike H, Saito K, Nakashima D, Higo M, Endo Y, Kasamatsu A, Shiiba M, Bukawa H, Yokoe $\mathrm{H}$ and Tanzawa H. Overexpression of stathmin in oral squamous-cell carcinoma: correlation with tumour progression and poor prognosis. Br J Cancer. 2006; 94:717-723.

8. Harada K, Ferdous T, Harada T and Ueyama Y. High expression of stathmin 1 is a strong prognostic marker in oral squamous cell carcinoma patients treated by docetaxelcontaining regimens. Clin Exp Med. 2015:1-6.
9. Belletti B and Baldassarre G. Stathmin: a protein with many tasks. New biomarker and potential target in cancer. Expert Opin Ther Targets. 2011; 15:1249-1266.

10. Jeon TY, Han ME, Lee YW, Lee YS, Kim GH, Song GA, Hur GY, Kim JY, Kim HJ, Yoon S, Baek SY, Kim BS, Kim JB and Oh SO. Overexpression of stathmin1 in the diffuse type of gastric cancer and its roles in proliferation and migration of gastric cancer cells. Br J Cancer. 2010; 102:710-718.

11. Jiang L, Chen Y, Chan CY, Wang X, Lin L, He ML, Lin MC, Yew DT, Sung JJ, Li JC and Kung HF. Downregulation of stathmin is required for TGF-beta inducible early gene 1 induced growth inhibition of pancreatic cancer cells. Cancer Lett. 2009; 274:101-108.

12. Rana S, Maples PB, Senzer N and Nemunaitis J. Stathmin 1: a novel therapeutic target for anticancer activity. Expert Rev Anticancer Ther. 2008; 8:1461-1470.

13. Liu F, Sun YL, Xu Y, Liu F, Wang LS and Zhao XH. Expression and phosphorylation of stathmin correlate with cell migration in esophageal squamous cell carcinoma. Oncol Rep. 2013; 29:419-424.

14. Hsieh SY, Huang SF, Yu MC, Yeh TS, Chen TC, Lin YJ, Chang CJ, Sung CM, Lee YL and Hsu CY. Stathmin1 overexpression associated with polyploidy, tumor-cell invasion, early recurrence, and poor prognosis in human hepatoma. Mol Carcinog. 2010; 49:476-487.

15. Nemunaitis J. Stathmin 1: a protein with many tasks. New biomarker and potential target in cancer. Expert Opin Ther Targets. 2012; 16:631-634.

16. Yuan RH, Jeng YM, Chen HL, Lai PL, Pan HW, Hsieh FJ, Lin CY, Lee PH and Hsu HC. Stathmin overexpression cooperates with p53 mutation and osteopontin overexpression, and is associated with tumour progression, early recurrence, and poor prognosis in hepatocellular carcinoma. J Pathol. 2006; 209:549-558.

17. Li J, Hu GH, Kong FJ, Wu KM, He B, Song K and Sun WJ. Reduced STMN1 expression induced by RNA interference inhibits the bioactivity of pancreatic cancer cell line Panc-1. Neoplasma. 2014; 61:144-152.

18. Zhao E, Amir M, Lin Y and Czaja MJ. Stathmin mediates hepatocyte resistance to death from oxidative stress by down regulating JNK. PLoS One. 2014; 9:e109750.

19. Wang S, Akhtar J and Wang Z. Anti-STMN1 therapy improves sensitivity to antimicrotubule drugs in esophageal squamous cell carcinoma. Tumour Biol. 2015; 36:7797-7806.

20. Miceli C, Tejada A, Castaneda A and Mistry SJ. Cell cycle inhibition therapy that targets stathmin in in vitro and in vivo models of breast cancer. Cancer Gene Ther. 2013; 20:298-307.

21. Koff JL, Ramachandiran S and Bernal-Mizrachi L. A time to kill: targeting apoptosis in cancer. Int J Mol Sci. 2015; 16:2942-2955. 
22. Meng ZJ and Tao K. Enhancement of Chemosensitivity by Stathmin-1 Silencing in Gastric Cancer Cells In Situ and In Vivo. Oncol Res. 2016; 23:35-41.

23. Wu Y, Tang M, Weng X, Yang L, Xu W, Yi W, Gao J, Bode AM, Dong $Z$ and Cao Y. A combination of paclitaxel and siRNA-mediated silencing of Stathmin inhibits growth and promotes apoptosis of nasopharyngeal carcinoma cells. Cell Oncol (Dordr). 2014; 37:53-67.

24. Chung MK, Kim HJ, Lee YS, Han ME, Yoon S, Baek SY, Kim BS, Kim JB and Oh SO. Hedgehog signaling regulates proliferation of prostate cancer cells via stathmin1. Clin Exp Med. 2010; 10:51-57.

25. Takahashi K and Suzuki K. Membrane transport of WAVE2 and lamellipodia formation require Pak1 that mediates phosphorylation and recruitment of stathmin/Op18 to Pak1WAVE2-kinesin complex. Cell Signal. 2009; 21:695-703.

26. Mizumura K, Takeda K, Hashimoto S, Horie T and Ichijo H. Identification of Op18/stathmin as a potential target of ASK1-p38 MAP kinase cascade. J Cell Physiol. 2006; 206:363-370.

27. Williams K, Ghosh R, Giridhar PV, Gu G, Case T, Belcher SM and Kasper S. Inhibition of stathmin 1 accelerates the metastatic process. Cancer Res. 2012; 72:5407-5417.

28. Liu RR, Li MD, Li T, Tan Y, Zhang M and Chen JC. Matrix metalloproteinase 2 (MMP2) protein expression and laryngeal cancer prognosis: a meta analysis. Int J Clin Exp Med. 2015; 8:2261-2266.
29. Wang HL, Zhou PY, Zhang Y and Liu P. Relationships between abnormal MMP2 expression and prognosis in gastric cancer: a meta-analysis of cohort studies. Cancer Biother Radiopharm. 2014; 29:166-172.

30. Ng DCH and Byrne F. (2012). Stathmin and Cancer. Cytoskeleton and Human Disease: Springer), pp. 259-284.

31. Wang R, Dong K, Lin F, Wang X, Gao P, Wei SH, Cheng $\mathrm{SY}$ and Zhang HZ. Inhibiting proliferation and enhancing chemosensitivity to taxanes in osteosarcoma cells by RNA interference-mediated downregulation of stathmin expression. Mol Med. 2007; 13:567-575.

32. Goldstraw P, Crowley J, Chansky K, Giroux DJ, Groome PA, Rami-Porta R, Postmus PE, Rusch V and Sobin L. The IASLC Lung Cancer Staging Project: proposals for the revision of the TNM stage groupings in the forthcoming (seventh) edition of the TNM Classification of malignant tumours. J Thorac Oncol. 2007; 2:706.

33. Biaoxue R, Xiling J, Shuanying Y, Wei Z, Xiguang C, Jinsui $W$ and Min Z. Upregulation of Hsp90-beta and annexin A1 correlates with poor survival and lymphatic metastasis in lung cancer patients. J Exp Clin Cancer Res. 2012; 31:70.

34. Biaoxue R, Xiguang C, Hua L, Hui M, Shuanying Y, Wei $\mathrm{Z}$, Wenli S and Jie D. Decreased expression of decorin and p57 (KIP2) correlates with poor survival and lymphatic metastasis in lung cancer patients. Int J Biol Markers. 2010; 26:9-21. 